\title{
Maximization of RES Utilization in Case of Crete's Interconnection
}

\author{
Emmanuel S. Karapidakis ${ }^{1}$
}

\begin{abstract}
Although, there is even higher capacity of RES that could be utilized, the current power system operation and control emerge limitations, which hold back their further exploitation. More precisely, this study analyses current island power system operation and demonstrates benefits and obstacles of an interconnection. The potential of ultrahigh share of RES is technically feasible, while provides under specific implementation strategies advantages in stability, reliability, and energy adequacy.
\end{abstract}

Keywords

Renewable energy sources, island power systems, interconnection.

\section{Acknowledgement (Header1: Abs-Keyw_Ack)}

This research has been co-financed by the European Union (European Social Fund - ESF) and Greek national funds through the Operational Program "Education and Lifelong Learning" of the National Strategic Reference Framework (NSRF) - Research Funding Program: ARCHIMEDES III. Investing in knowledge society through the European Social Fund.

\section{Introduction}

Maximization of wind and solar power exploitation is particularly attractive [1, 2], but as far as it concerns island a careful consideration is needed, so as to maintain a high degree of reliability and stability of the system

\footnotetext{
${ }^{1}$ School of Applied Science,

Technological Educational Institute of Crete Estavromenos Campus 71004, Heraklio, Greece (e-mail: karapidakis@ staff.teicrete.gr)
}

operation [3-5]. The main problems identified concern operational scheduling (mainly unit commitment) due to high production forecasting uncertainties.

These problems may considerably limit the amount of wind and PV generation that can be installed to noninterconnected island systems, increasing the complexity of their operation.

At the other side, by their geographical and natural position, European Islands represent a key actor with specific characteristics into the implementation framework of a sustainable energy policy. More precisely, three main dimensions have been identified by the European Commission for a successful energy planning, which are security of supply, sustainability and competitiveness. Furthermore, several obstacles and technical restrictions are evident in island's the energy sector, such as higher total costs, fluctuations in the price and insecurity of supply. However, these disadvantages can be outweighed by inherent advantages, especially by utilization of renewable energy technologies, thanks to their relative high wind and sun exposure. This potential should be better exploited in order to investigate the operation and planning limitations and estimate the possible solutions.

The new operating and planning policies imposed by the current demands for increased efficiency and economy, dictate the need to operate the power system in a more stressed way. More precisely, several previous studies have analyzed the feasibility, and benefits of high percentage electricity supply from RES technologies in Crete. Crete's power system faces already a significant contribution up to $25 \%$ in its energy balance by renewable energy sources.

But even though, there is even more capacity of RES

This is an Open Access article distributed in accordance with the Creative Commons Attribution Non Commercial (CC-BY-NC-ND 4.0) license, which permits others to copy or share the article, provided original work is properly cited and that this is not done for commercial purposes. Users may not remix, transform, or build upon the material and may not distribute the modified material (http://creativecommons.org/licenses/by-nc/4.0/) 
that could be utilized, the current power system operation has restrictions that hold back their further expansion. More precisely, this study analyses current system operation and demonstrates benefits and obstacles of an interconnection with the mainland of Greece in parallel with local units' installation. Nevertheless, the possibility of an significant large share of RES is technically feasible, while provides under specific implementation strategies advantages in stability, reliability, and energy adequacy.

\section{Power System of Crete's Island}

As it is well known [3-4] island power systems face increased problems related to their steady state operation and dynamic performance, since mismatches in generation and load and/or unstable system frequency control might lead to system failure much easier compared to conventional interconnected systems.

This study deals with the autonomous power system of Crete island, where renewable energy sources exploitation, especially wind and solar energy, are significant. Crete island has already a considerable amount of installed wind park and PV plants with almost $18 \%$ contribution in annual energy balance. However, the integration of a higher percentage of RES penetration, especially of wind power, needs careful consideration, so as to maintain high levels of reliability and security of the system operation [6].

Conventional generation is based on three (3) oilfired thermal power units with total capacity of $700 \mathrm{MW}$ approximately. Additionally, there are 23 wind parks installed with nominal power of 170MW across the island as it is depicted in Fig.1. Furthermore, 1200 small PV plants of $80 \mathrm{~kW}$ nominal power each are already installed (Fig. 2) giving 80MW in total.

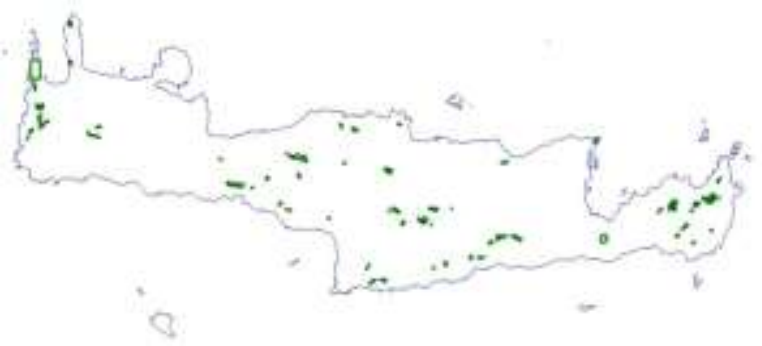

Fig. 1 Wind parks allocation

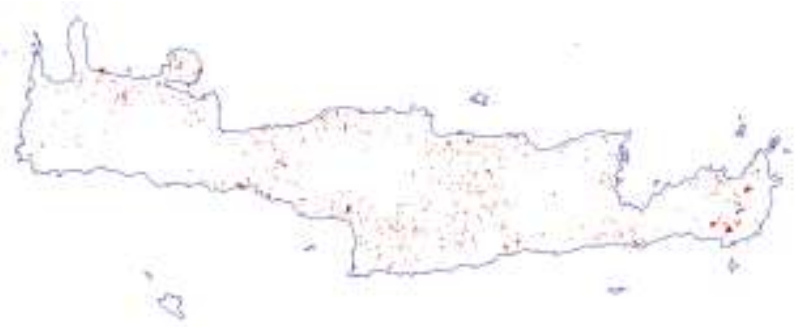

Fig. 2 PV plants allocation

Fig. 3 shows the corresponding share of wind and solar power in the island's energy balance. In this case, small scale RES installations are not included due to lack of procedures for monitoring or supervising. These installations contribute only to the load demand decrement.

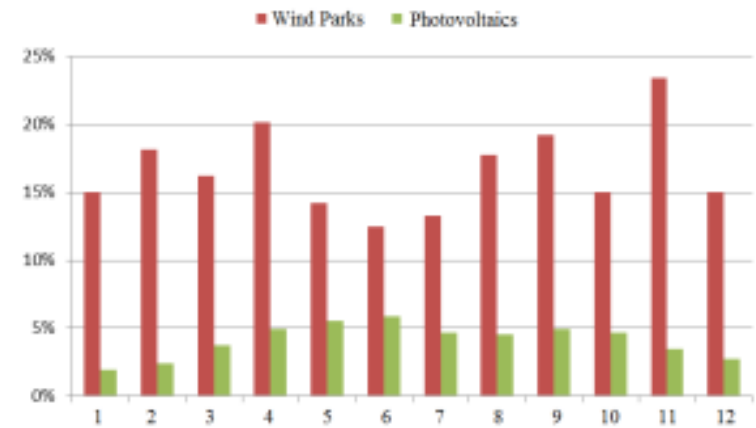

Fig. 3 PVs and WPs monthly energy contribution.

\section{Interconnection of Crete's island}

Interconnection of Crete's system with the mainland system has been the basis of several recent studies. Many of these studies take into account future further interconnections expansion, such as the rest of the Aegean islands, and other areas as power system of Cyprus and Northern Africa. The most critical and common points of these studies are the interconnection type and volume, the corresponding buses which will be interconnected in each power system and the optimal design regarding the use of local conventional plants and the renewables generation, respectively. Therefore in this section the proposed scenarios for the island's interconnection are presented, starting with the proposals supplied by two independent producers in order to be able to supply power to the mainland by a large number of proposed wind parks projects.

First Interconnection Proposal: In this proposal, a large number of wind parks, $1.002 \mathrm{MW}$ in total, will be installed in the island. These wind parks will be connected as an ultra large wind farm directly to the mainland system through a HVDC submarine cable. More 


\section{E. S. Karapidakis \\ Maximization of RES Utilization in Case of Crete's Interconnection}

precisely, connection points will be the western part of Chania and the southern part of Peloponnese, respectively.

Second Interconnection Proposal: In this proposal, thirty three (33) wind parks are about to be installed. The nominal power of $1.077 \mathrm{MW}$ in total will be available to the mainland grid through another submarine HVDC link. In this case too, wind parks will not be connected to the local grid, at least in the first phase of the project.

Third Set of Proposals: At the other hand, the final set of proposals submitted by the transmission system operator (TSO) separates the interconnections from any wind park installation project. Thus in this case, there are several proposed options of interconnection type and connection points, respectively.

More precisely, there are proposed two scenarios of connection points:

- Chania region - Megalopoli region, $(250 \mathrm{~km}-400 \mathrm{kV}$ DC Link, 120km AC line) as it is showed in Fig. 4.

- Heraklio region (Linoperamata or Korakia) - Athens region (Lavrio), $(380 \mathrm{~km}-400 \mathrm{kV}$ DC Link), as it is showed in Fig. 5.

An extended scenario takes into account both of the previous mentioned interconnection DC links, increasing significantly the reliability and the general performance of the system. Thereinafter, the proposed types of DC link and their corresponding power capacity are Voltage source converter (VSC based HVDC) with the use of IGBTs (Insulated Gate Bipolar Transistors) and capacity levels of 700MW (2x350MW), 1000MW (1x1000MW/ $2 \times 500 \mathrm{MW})$ and 2000MW (2x1000MW).

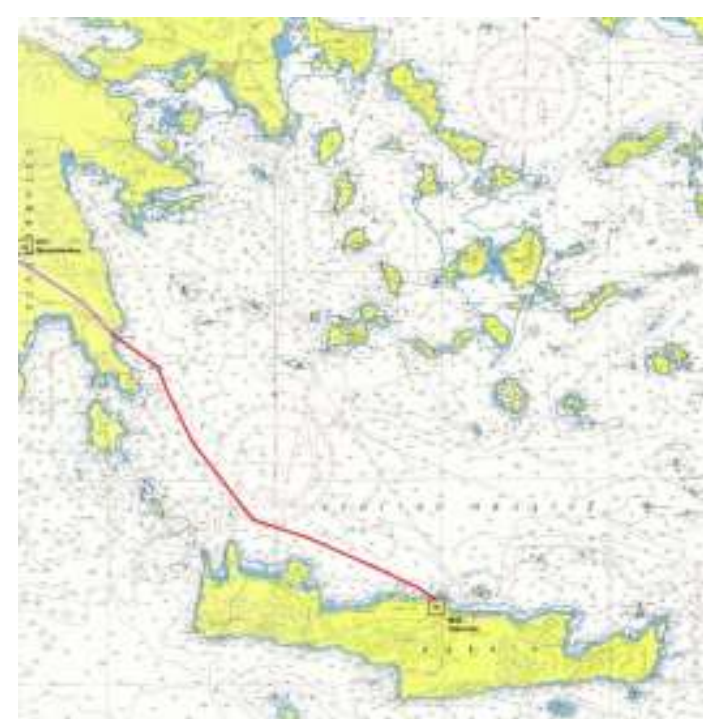

Fig. 4 First proposed interconnection

Furthermore, one more critical issue regarding interconnection power capacity level is the operational status of the local conventional power plants. Thus, two (2) main approaches have resulted:

- Keep all or most of the local power plants in hot spinning reserve, In order to preserve an adequate stability and reliability level, taking into account the special characteristics of Crete's power system.

- Keep all or most of the local power plants in cold spinning reserve. In this case, there is a need of two different interconnection links or installation and utilization of local energy storage systems.

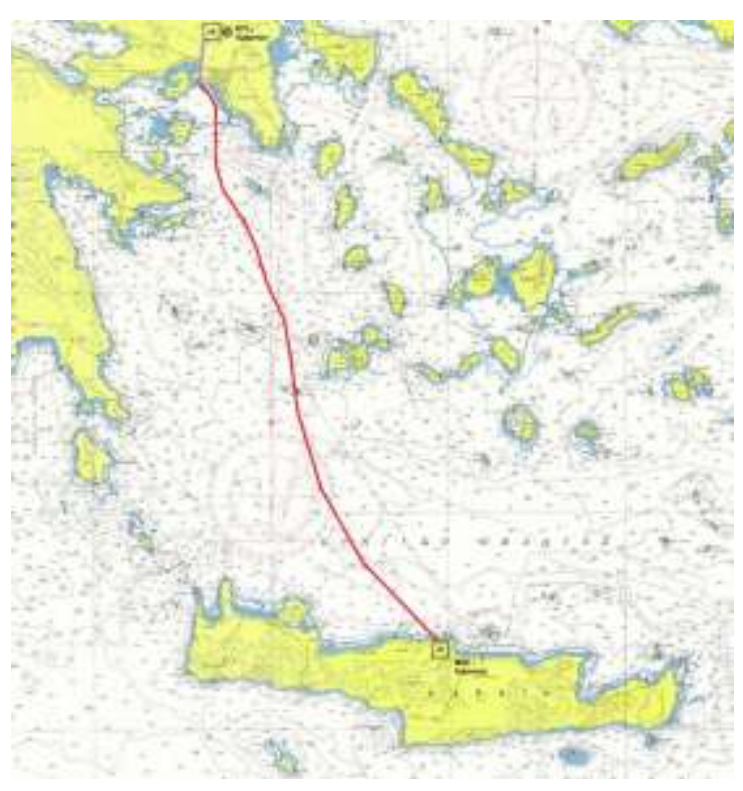

Fig. 5 Second proposed interconnection

\section{Operation Analysis}

This paper presents and analyses the development and the operation of interconnected power system of Crete under several scenarios. More precisely, the main variables of this study are:

- Range of installed wind power,

- Development and operation of pump energy storage systems (input varies from $0 \mathrm{MW}$ to 250MW).

- Operation of the three local conventional plants (input varies from 700MW to $0 \mathrm{MW}$ ).

- Type, volume and number of the DC Links (case of 700MW, 1000MW and 2000MW, case of one DC link and two different DC links.

Taking into account all the previous system variables a representative set of 112 subcases were developed. Then these subcases had been simulated under two (2) different 
scenarios of power flow over the examined DC links.

- Case of high power flow on the DC link due to peak load demand and low wind power generation.

- Case of high power flow on the DC link due to high wind power generation and low load demand.

Finally, all these developed subcases had been simulated in steady study analysis using relevant software (Matlab/Simulink/Powerworld). The main purpose was to estimate the level of further RES utilization on the island and especially further wind power exploitation.

The examined performance of the Crete's system remained in marginally acceptable levels till the value of $1236 \mathrm{MW}$ installed wind power, including the existing wind parks on the island. In parallel, all the subcases presented better performance when significant number of local units were in operation, both in case of low or high power flow over DC link. The most crucial case regarding both weak load flow profile and unstable performance was the case of none local conventional units in operation.

\section{Conclusion}

The most critical and common points of these studies are the interconnection type and volume of Crete's power system with the mainland, the corresponding buses which will be interconnected in each power system and the optimal design regarding the use of local conventional plants and the renewables generation, respectively. Therefore in this paper the proposed scenarios for the Crete's interconnection were presented.

More precisely, this study has examined (a) three different cases of interconnection types regarding capacity 700MW, 1000MW and 2000MW, two different cases of DC link types S-momopole and bipolar VSC-HVDC, (b) the operation of all the planned to be installed pump storage units up to $250 \mathrm{MW}$ in total, (c) the operation strategy of the local conventional power plants and finally (d) further wind power utilization till $2.74 \mathrm{GW}$ in total.

In conclusion the results of this preliminary study indicated that implementation and operation of Crete's interconnection (DC link) with the mainland in parallel with an adequate local conventional generation will clearly assist the further wind power utilization on the island up to $1236 \mathrm{MW}$ keeping sufficiently the required level of reliability and stability [6, 7].

\section{References}

[1] J. Stefanakis. "Crete: An ideal case study for increased wind power penetration in medium sized autonomous power systems", in Proc. IEEE Power Engineering Society (PES) Winter Meeting, pp. 329-334, (2002).

[2] Zografakis, N., 2005. "CRETE: A preferential island for extensive applications of renewable energy sources in Europe and Mediterranean," International Conference on Renewable Energy for Islands, Brussels, 21 September.

[3] Papathanasiou; S., Boulaxis, N., (2006). Power limitations and energy yield calculation for wind farms operating in island systems, Elsevier, Renewable Energy, 31, (4), pp. 457-479.

[4] Karapidakis, E.S., Thalassinakis, M., 2006. “Analysis of Wind Energy Effects in Crete's Island Power System”. 6th International World Energy System Conference, Turin, Italy, July 2006.

[5] Kaldellis, J.K., Kavadias, K.A., Filios, A.E, 2009. "A new computational algorithm for the calculation of maximum wind energy penetration in autonomous electrical generation systems". Applied Energy 86 (7-8), pp. 1011-1023.

[6] N. Hatziargyriou, G. Contaxis, M. Matos, J. P. Lopes, G. Kariniotakis, D. Mayer, A. P. Figueira. "Energy management and control of island power systems with increased penetration from renewable sources", in Proc. IEEE Power Engineering Society (PES) Winter Meeting, pp. 335-339, (2002).

[7] Smith, P., O’Malley, M., Mullane, A., Bryans, L., Nedic, D. P., Bell, K., Meibom, P., Barth, R., Hasche, B., Brand, H., Swider, D. J., Burges, K., Nabe, C., 2006. "Technical and Economic Impact of High Penetration of Renewables in an Island Power System”. CIGRE Session 2006, Paper C6-102. 